\section{Prof. Hantaro Nagaoka}

Prof. Nagaoka was born on August 18, 1865, when Japan was in the midst of turmoil centring on the problem of the re-opening of trade and diplomatic relations with European countries and the United States after two hundred years of isolation from the rest of the world. He graduated from the College of Science of Tokyo Imperial University (now the University of Tokyo) in 1887, not long after it had been established by the new government. $\mathrm{He}$ obtained his doctorate in 1893 and, after having studied further in Germany for three years, he was appointed professor of physics at Tokyo Imperial University and held that position from 1896 until 1926. From 1926, he continued to carry out research at the Institute of Physical and Chemical Research (now Scientific Research Institute) in Tokyo until 1945. Even after he left the Institute, he was actively engaged in research work up to the very end of his life, which came on December 10, 1950, at the age of eighty-five.

Prof. Nagaoka published more than three hundred scientific papers covering a wide range of pure and applied physics, extending from hyperfine structure of atomic spectra to the theory of earthquakes. His earliest work on geophysics was followed by the investigation of magnetism, which was further extended by $\mathrm{K}$. Honda. Then his interest turned to spectroscopy. In his latest years, he returned to various subjects on geophysics. Among numerous papers, however, he is best known by his pioneering work on the atom model, which appeared in the Philosophical Magazine in 1904. His Saturn model of the atom could be regarded, in a sense, as the forerunner of the Rutherford-Bohr theory. It is also worth while mentioning that he predicted the existence of the ionosphere quite independently of Kennelly and Heaviside.

Prof. Nagaoka was elected a member of the Imperial Academy of Japan (now the Japan Academy) in 1905 and was president of the Academy during 193948. He was the first president of Osaka (Imperial) University, which was established in 1931. He was elected an honorary member of the Physical Society of Japan in 1950 and was among the first who received in 1937 the Order of Cultural Merit, a medal of high distinction. Honours came also from abroad. He was elected an honorary fellow of the Physical Society of London in 1912, and received in 1925 , the honorary degree of doctor of philosophy from the University of Cambridge.

His influence, both direct and indirect, was great on a large number of younger Japanese, who looked up to him as an outstanding native scientist, as they were eager to catch up with Western science and technology. He was a born scientist with a genuine love of Nature. His tireless endeavour for nearly sixty years in search of truth justly earned his reputation. HIDEKI YURawa

\section{Dr. C. D. Perrine}

WE record with regret the death, which occurred on June 21, 1951, at the age of eighty-three years, of Dr. Charles D. Perrine, former director of the Cordoba Observatory, Argentine. Dr. Perrine began his astronomical career at the Lick Observatory in 1893. He made many observations of comets, and was active in discovering them, his discoveries including comets 1895 IV, 1896 I, 1896 VII (periodic),
1897 I, 1897 III, 1898 I, 1898 VI, 1898 IX, 1902 III. He was also the first to observe the periodic comets, D'Arrest at its return in 1897 , Pons-Winnecke at its return in 1898, and Temple (2) at its return in 1899. In 1904 he discovered, on photographs with the Crossley reflector, the sixth satellite of Jupiter, and the following year the fainter seventh satellite; these two satellites form a pair with nearly the same mean distances (about seven times greater than that of the most distant of the previously known satellites) and have interlocking orbits. Their motions are subject to large perturbations. From observations with the Crossley reflector of Nova Persei 1901, Perrine discovered the expanding nebulosity around the nova, caused by the light from the outburst as it travelled outwards, illuminating the interstellar cloud in which the nova happened to be. From his observations of faint spiral nebulæ he was able to conclude that the number of such systems discoverable with this telescope was about half a million, providing the first evidence of the vast number of these objects, which has been fully confirmed by later observations. In 1903 he succeeded in obtaining the spectrum of Nova Auriga (1891) which was then of the 14th magnitude, and showed that it consisted of bright lines superposed on a continuous spectrum.

In 1909 Perrine left the Lick Observatory to take up the appointment of director of the Cordoba Observatory, a position which he held until his retirement in 1936. A fine series of photographs of Halley's Comet at its return in 1910, together with measure. ments of position and of brightness, were obtained, which formed the basis of a large volume, published in 1934, which contained excellent reproductions of many of the photographs, together with the observations and their discussion. Sixteen volumes of the "Resultados del Observatorio Nacional Argentino" were published under his direction. By his energy and enterprise, Perrine was responsible for the creation of the Astrophysical Station at Bosque Alegre, with its 60 -in. reflector.

Perrine was interested in eclipse observations. He led the Lick expedition to Sumatra in 1901 to observe .the total eclipse of May 18 that year, which secured successful observations. In 1914 he joined with Dr. W. W. Campbell, director of the Lick Observatory, in an expedition to the Crimea to observe the eclipse of August 21. Observations were hindered by clouds and the return journey was complicated by the out. break of the First World War.

Perrine was awarded the Lalande prize of the Paris Academy of Sciences in 1897. In 1902 he was president of the Astronomical Society of the Pacific. He was elected an Associate of the Royal Astronomical Society in 1904, and at the time of his death was the senior, by nine years, of the Associates of the Society.

H. SPEncer Jones

WE regret to announce the following deaths :

Prof. Gilbert Cook, F.R.S., emeritus professor of civil engineering and mechanics in the University of Glasgow, on August 28.

Prof. 'T. H. Johnston, professor of zoology in the University of Adelaide, known for his work on the control of prickly pear in Australia, on August 30, aged sixty-nine.

Prof. G. Steindorf, formerly professor of Egyptology in the University of Leipzig, on August 28, aged eighty-nine. 